\title{
HEGEL, SCIENCE, AND SET THEORY
}

Much recent work in the philosophy of science has been concerned with the problem of the growth of scientific knowledge. This work has provided an important corrective to positivist philosophy of science and analytic epistemology, which have concentrated on describing the structure of knowledge. Through the efforts of Kuhn and other historically oriented philosophers ([16], [17], [18]), it has become increasingly clear that any account of the structure of knowledge must be sufficiently rich to accommodate a complex account of how knowledge grows. The enterprise of developing an integrated description of the growth and structure of knowledge might be termed "historical epistemology".

Hegel was one of the first historical epistemologists. His dialectic can be taken as a general theory of development, but with special applicability to the development of knowledge. There are important structural similarities between the dialectic and the growth of scientific knowledge, although there are also interesting differences. To bring out the similarities and differences, I offer a set-theoretic formalization of the dialectic. I do not thereby claim to have formalized Hegel's dialectic, a truly formidable project on which numerous attempts have been made ([1], [3], [6], [15], [23], [24], [25], [36]). The task of giving a fully adequate representation of the dialectic probably outstrips any formal technique, since the dialectic has many conceptual and pragmatic aspects. Nevertheless, it is possible formally to capture some of the essential features of such central notions as dialectical negation and contradiction, Aufheben, and the Absolute. The formalism then can be used to exhibit parallels between Hegel's account of the growth of knowledge and contemporary views on theory change.

It is commonly believed that an essential feature of Hegel's dialectic is the admission of logical contradictions. R. Routley and R. K. Meyer [24] use relevance logic to accommodate contradictions of the sort $p \& \sim p$, but I take this to be at best an incidental aspect of Hegel's dialectic. Hegel's dialectic essentially concerns the dynamics of conceptual structures, and a formalization can be based on the following conclusions. (1) Dialectic "logic" is not a logic of sentences or propositions, but a general 
theory of the development of conceptual structures. (2) These conceptual structures can best be represented not syntactically, but set-theoretically, using the formalism developed for the "non-statement" or "structuralist" account of scientific theories by J. D. Sneed [26] and W. Stegmüller [27], [28]. (3) The structure of Hegel's dialectic bears important similarities to the structure of the growth of scientific knowledge as interpreted in a nonpositivist manner; in particular each stage of the dialectic bears the same sort of complex relation to the previous stage as a scientific theory does to its predecessor. (4) Hence the Sneed-Stegmüller account of the dynamics of theories can be adapted to provide a formalization of Hegel's dialectic.

Hegel's thought is complex and difficult, but it is possible to present the central features of the dialectic with a minimum of obscurity. I take dialectic to be a general theory of development. Hegel says that "wherever there is movement, wherever there is life, wherever anything is carried into effect in the actual world, there Dialectic is at work." ([9], p. 148.) Hegel himself applies the dialectic to consciousness in [10], to history in [11], to the history of philosophy in [8], and in full generality to logical categories in [12]. In the first of these, Hegel describes the development of consciousness from a form having only the most primitive kind of knowledge to the form which is capable of absolute knowledge. In the last, he describes the development of the "Notion" from the most primitive category, Being, to a category which encompasses everything, the Absolute Idea. According to Hegel, the structure of each process is the same, for he says of consciousness that "the development of this object, like the development of all natural and spiritual life, rests solely on the nature of the pure essentialities which constitute the content of logic." ([12], p. 28.) However, the relation of Hegel's dialectic to the growth of scientific knowledge is much clearer in the dialectic of stages of consciousness in [10] than in the pure dialectic of concepts in [12], since the Phenomenology [10] is specifically concerned with the development of knowledge by a subject. Hence my discussion is primarily relevant to the dialectic of consciousness described in that work.

Each stage in the dialectial process gives rise to a succeeding stage which is said to be its negation. This notion of negation is very different from anything in propositional logic. The result of a dialectical, or "determinate" negation ([10], p. 137) is very complex: each new stage both supersedes and incorporates the stage which it negates. ([9], p. 152, [12], p. 54.) 
The process is best described by the untranslatable German verb Aufheben, since its meaning includes both (1) to clear away or annul, and (2) to keep or preserve. ([9], p. 180, [12], pp. $106 \mathrm{ff}$.) By means of such operations of supersession and incorporation, progress is made toward the Absolute. Negation in each stage is necessitated by the possession of the stage of internal "contradictions" which show that the Absolute has not yet been reached.

The double aspect of dialectical negation and Aufheben makes formal representation very difficult. It would be tempting to take two dialectical stages $S_{i}$ and $S_{j}$ as propositions, define some negation operator $N$, then arrive at some such formula as $S_{j}=N\left(S_{i}\right)$ or $N\left(S_{i}\right) \rightarrow S_{j}$. But syntactic means appear insufficient to capture the incorporating aspect of negation. Moreover, we must account for the properties of the negation of the negation, which, Hegel stresses, "is not a neutralization." ([9], p. 178.) The propositional law of double negation does not apply in dialectics, since a second operation of negation leads on to a new, higher, more complex stage. The notion of the Absolute as the terminus of the process of successive negation also seems inaccessible to syntactic treatment.

To the rescue comes the set-theoretic apparatus of Sneed and Stegmüller. It should not seem odd that a formalism dealing with scientific theory change is applicable to Hegel's dialectic. Errol Harris [7] has described numerous parallels between dialectic and scientific method. Criticisms of positivist views of science have pushed the philosophy of science in several Hegelian directions, involving discussion of such topics as the dynamics of theories, conceptual change, and competition among theories. ([5], [16], [17], [34].) On the positivist view of the growth of science, a theory subsumed previous ones in a steady process of accumulation. Formally this can be expressed as the deduction of a reduced theory, $T_{i}$ from a reducing theory $T_{j}$ plus bridge laws and coordinating definitions, where a theory is taken to be a set of sentences. Kuhn and others have argued that the degree of conceptual change from $T_{i}$ to $T_{j}$ is such that scientific progress should not be viewed as mere accumulation. Instead, we seem to have a relation much like dialectical negation! $T_{j}$ preserves the accomplishments of $T_{i}$, but at the same time supersedes it in a conceptually radical manner. (Cf. [7], p. 14) Sneed and Stegmüller make a sophisticated attempt to capture this complex relation of theory replacement, and their methods can be adapted to Hegel's dialectic. 
The adaptation is appropriate for an additional reason. Sneed and Stegmuiller abandon the positivist view that a theory is a set of sentences, proposing instead that a theory is a conceptual structure characterized settheoretically. Such a semantic approach to the philosophy of science has also been advocated by F. Suppe [29], P. Suppes [30], [31], and B. van Fraassen [37]. Of course the use of set theory was unknown to Hegel, but not so the view that the representation of knowledge is essentially nonsentential. He says that "the propositional form ... is not suited to express the concrete - and the true is always concrete - or the speculative." ([9], p. 65) Both the Phenomenology of Mind and the Science of Logic employ a holistic epistemology (the true is the whole: [10], p. 81) which is much more consonant with the Sneed-Stegmüller approach than with the traditional Anglo-American epistemology. Heidegger seems similar to Hegel in his claim that assertion is only a derivative mode of interpretation. ([13], pp. $195 \mathrm{ff}$.) Another parallel is found in recent work in cognitive psychology and artificial intelligence, where many researchers have supplemented sentential representations of knowledge in favor of representations employing larger data-structures called frames. (See [21], [35].)

So much for preamble. I shall now present a simplified version of the formalism of Sneed and Stegmüller. Much of their apparatus, such as the construction of Ramsey sentences and the introduction of "partial possible models", can be omitted here because it concerns the problem of theoretical terms, which does not arise for Hegel.

According to Sneed and Stegmüller, the main functions of a theory are to pick a class $M$ of models (in Tarski's sense ${ }^{2}$ ) out of a class of possible models $M_{p}$, and to specify $I$, the set of intended applications for $M . M$ could be specified formally by an axiom system, where $M$ consists of those elements of $M_{p}$ which satisfy the axioms and theorems of the system, or more directly in the manner of P. Suppes by means of a set-theoretic predicate. ([30], pp. 249 ff.) But without such specification we can still talk generally of a theory as a structure $\langle K, \eta\rangle$, where $K$ is said to be the core of the theory consisting of the pair $\left\langle M, M_{p}\right\rangle$, such that $M \subset M_{p}$, and $I$ is the set of the intended applications such that $I \subset M_{p}$. A theory construed as such a structure cannot be said to be true or false, but it can be used to make a basic claim. ([27], p. 48.) The claim is that the models which constitute the intended applications of the theory are in fact among the models picked out by the theory: $I \subset M$. For scientific theories, the 
basic claim is an empirical one, asserting the adequacy of the theory in representing empirical phenomena; but in Hegel's dialectic, the basic claim will be purely conceptual.

We can identify stages of the dialectic with conceptual structures $S$ of the form $\langle K, I\rangle$. Let $S_{i}=\left\langle K_{i}, I_{i}\right\rangle$ where $K_{i}=\left\langle M_{i}, M_{p}\right\rangle$, and let $S_{j}=$ $\left\langle K_{j}, I_{j}\right\rangle$ where $K_{j}=\left\langle M_{j}, M_{p}\right\rangle$. Now we can characterize: $S_{j}$ is a dialectical negation of $S_{i}$ if and only if

(1) $\quad I_{i} \subset I_{j}$

(2) $\quad M_{i} \notin M_{j}$

(3) $\quad\left(I_{i} \cap \bar{M}_{i}\right) \subset M_{j}$.

Pictorially, the situation is as in Figure 1:

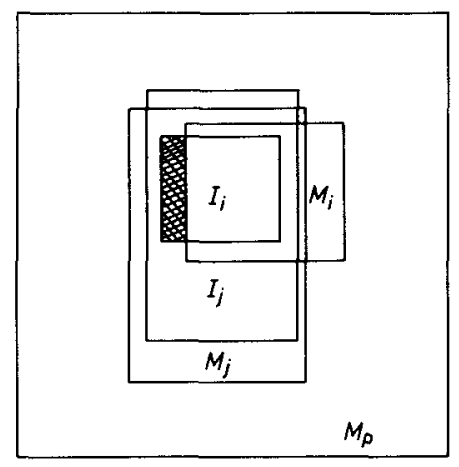

Fig. 1.

As desired, $S_{j}$ both surpasses and incorporates $S_{i}$. The incorporation is represented in clause (1) by the fact that $S_{j}$ has all the applications which $S_{i}$ has. In terms of scientific theories, we could say that $S_{j}$ explains everything which $S_{i}$ did. But the transition from $S_{i}$ to $S_{j}$ is not simply cumulative since clause (2) guarantees that $S_{j}$ and $S_{i}$ pick out different models. The motivation of clause (3) is more complex: we suppose that the inadequacy of stage $S_{i}$ derives from its failure to include among its models $M_{i}$ some of its intended applications $I_{i}$. Then the shaded area $I_{i} \cap \bar{M}_{i}$ is very significant. Call this the set of "anomalies" of $S_{i}$, since if we were thinking of $S_{i}$ as a theory, we would consider $I_{i} \cap \bar{M}_{i}$ to represent phenomena which $S_{i}$ is supposed to deal with but does not. (Cf. [16], ch. VI.) $S_{j}$ shows itself 
to be a proper replacement for $S_{i}$ by including the anomalies of $S_{i}$ among its models $M_{j}$.

We can say that the "contradiction" in $S_{i}$ which necessitates its supersession is between the claim that $I_{i} \subset M_{i}$ and the existence of anomalies $I_{i} \cap \bar{M}_{i}$. In the context of the dialectic, this contradiction is "real", since for the idealist Hegel conceptual structures are real. Although we have a logical contradiction between the claim and the recognition of the existence of anomalies, Hegel's notion of contradiction is clearly more complex than that discussed by Routley and Meyer [24], since it is a contradiction involving a specific sort of claim, not just any $p \& \sim p$. Moreover, the significance of Hegel's notion of contradiction is dynamic, indicating the need to move on to a higher stage $S_{j}$.

$S_{j}$ resolves the contradiction in $S_{i}$ by including the anomalies in $M_{j}$, as required by clause (3). Incorporation of the anomalies is thus represented, although what is more important is that $S_{j}$ has succeeded in overcoming the contradiction which defeats $S_{i}$. Of course, we expect that $S_{j}$ will have its own anomalies as represented in the above picture by the non-emptiness of $I_{j} \cap \bar{M}_{j}$. $S_{j}$ will then in turn be negated by some $S_{k}$. Obviously the negation of the negation $S_{k}$ will not be equivalent to $S_{i}$. Finally, note that if $S_{j}$ were justified in its claim that $I_{j} \subset M_{j}$, then clause (3) would follow from clause (1). Clause (3) would take on much greater importance if we weakened clause (1) so as not to require that all of $I_{i}$ be in $I_{j}$. This would be in accord with suggestions by L. Laudan [18] and others that in scientific growth some applications are simply abandoned, but the weakening of clause (1) does not appear necessary for the representation of dialectic.

The formalization of negation given by clauses (1)-(3) obviously allows the existence of more than one $N\left(S_{i}\right)$ for each $S_{i}$. To tighten matters up, we can introduce an additional clause requiring that $S_{j}$ go no further beyond $S_{i}$ than necessary to deal with the intended applications of $S_{i}$. We then add to the definition of negation:

$$
\left(M_{j} \cap I_{j}\right)=I_{i}
$$

This restricts $S_{j}$ to having as actual applications only the intended applications of $S_{i}$. The limitation is consonant with Hegel's conception of the dialectic as a gradual process, devoid of unnecessary leaps. However, clause (4) is not consistent with the growth of scientific knowledge where 
we do not expect a theory to explain successfully only what its predecessor intended to explain; it should also deal with unanticipated phenomena. ${ }^{3}$

It can be objected that the above account is too conservative in supposing that the background class of possible models $M_{p}$ remains the same in the transition from $S_{i}$ to $S_{j}$. As Kuhn and others have argued, scientific advance often involves dramatic conceptual changes; and Hegel's own examples of dialectical development also seem to involve the enrichment and replacement of concepts. Hence we would have to distinguish a set of possible models $M_{p_{i}}$ for $S_{i}$ from a set $M_{p_{j}}$ for $S_{j}$, without requiring that $M_{p_{i}} \subset$ $M_{p_{j}}$. But this does not present any serious problem for the above definition of dialectical negation, since Hegel does not subscribe to the radical conceptual incommensurability which seems to be proposed by Kuhn. Hence we can presume the existence of considerable overlap between $M_{p_{i}}$ and $M_{p_{i}}$, so that clauses (1)-(4) are not vitiated. All we need is the condition that $I_{i} \subset M_{p_{i}}$. This condition would not be appropriate for scientific progress as described by Laudan and Kuhn, but it does fit with the cumulative nature of the dialectic, in which nothing is lost on the way to absolute knowledge.

In the case of radical incommensurability between $S_{i}$ and $S_{j}$, we would find that $M_{p_{i}} \cap M_{p_{j}}$ is the null set. It would then also follow that $I_{i} \cap I_{j}$ is the null set, and my definition of dialectical negation would be empty. However, despite some of Kuhn's more extreme remarks, successive theories in science do not seem so fully incommensurable. We can grant that the concept of mass in relativity theory is importantly different from the concept of mass in Newtonian mechanics, without supposing that the two theories represent different "worlds". Both theories are intended to apply to such systems of objects as our solar system. Hence there is at least some overlap between $I_{i}$ and $I_{j}$ and hence between $M_{p_{i}}$ and $M_{p_{j}}$. Similarly in Hegel, dialectical development is not so revolutionary as to require a continually novel set of possible models. Such a requirement would be incompatible with Hegel's profession that the meaning of Aufheben includes preservation as well as supersession. For preservation of previous stages in the dialectic, we must have considerable continuity in the possible models corresponding to the stages. In particular, we must have $I_{i} \subset I_{j}$, as clause (1) specifies. Otherwise, the relation between successive stages would be fully mysterious, and no notion of dialectical progress toward the Absolute would be possible. 
In sum, $S_{j}$ incorporates the applications of $S_{i}$ while introducing a novel conceptual structure adequate for the anomalies with which $S_{i}$ did not deal. Compare the first stage of the dialectic of consciousness in [10], which, Charles Taylor has remarked ([32], p. 145), fits well Hegel's own description of the ascending dialectic. Taylor describes the general operation of the dialectic in the Phenomenology as follows:

We start off with something which is intrinsically characterized by the purpose it is bent on realizing or the standard it must meet. We then show of this thing that it cannot effectively fulfill this purpose or meet the standard (and the 'cannot' here is one of conceptual necessity). We are up against a contradiction ([32], p. 131).

Thus the stage of consciousness makes a basic claim concerning a purpose or standard, only to founder on anomalies which refute the claim. The claim made by sense-certainty, which is the first stage of consciousness in [10], is to provide "immediate knowledge, knowledge of the immediate", which is a "knowledge of endless wealth" ([10], p. 149). Sense-certainty is supposed to achieve this rich, immediate knowledge through a kind of radical empiricism, involving pure sense experience with no conceptual contribution. But Hegel argues that sense-certainty soon discovers the contradiction that mediation by means of universal concepts is unavoidable. Taylor summarizes this discovery as follows:

Sensible certainty is supposed to be immeasurably rich compared to conceptual consciousness because nothing has yet been selected, or abstracted, or put in a category with other phenomena not now present. The whole scenery is there in its richness and particularity. But now we see that in order to know something about it we have to focus on some dimension or other of the reality before us. The great richness of this form of consciousness turns out to be merely apparent ([32], pp. 142f).

Hegel takes sense-certainty through several sub-stages designed to show the impossibility of unmediated knowing of particulars designated by "this", "here", or "now". He argues that the failure of sense-certainty requires moving on to a stage of consciousness called perception, which accommodates the mediation and universality which eliminated sensecertainty by viewing an object not as a bare sense-datum but as a thing with properties. In terms of my formalism, perception is the $S_{j}$ which negates the $S_{i}$ sense certainty. Sense certainty has as its intended applications knowledge of particulars designated by "this", "here" and "now". 
But these examples show themselves to be anomalies since they cannot be accommodated within the barren conceptual structure of sense-certainty. Instead, they are dealt with by the much richer resources ("models") of perception. Perception is the dialectical negation of sense-certainty, since: (1) perception is intended to deal with all the knowledge which sensecertainty is, so that $I_{i} \subset I_{j}$; (2) perception uses very different conceptual assumptions than sense certainty, so that $M_{i} \notin M_{j}$; and (3) perception successfully deals with the knowledge of particulars which constituted anomalies for sense-certainty, so that $\left(I_{i} \cap \bar{M}_{i}\right) \subset M_{j}$. Perception in turn proves inadequate and gives way to understanding which employs a dynamic conception of force. Thus my formalization conforms to the early stages of the dialectic in the Phenomenology.

Analogous developments can be found in the history of science. In the eighteenth century the dominant optical theory was Newton's theory that light consists of particles. This encountered anomalies concerning such phenomena as diffraction and polarization. It was superseded in the nineteenth century by the wave theory of Young and Fresnel, which explained phenomena of reflection and refraction as successfully as the particle theory did, but also dealt with diffraction and polarization. But the wave theory also encountered anomalies or "contradictions", especially concerning the existence of the ether, and was in turn "negated" by the photon theory of Planck and Einstein.

The point of the dialectical process is to achieve the stage where contradictions no longer arise; this ultimate, self-sufficient stage is called Absolute knowledge. We can develop a formal notion of the Absolute by considering the set $I$ of intended applications. In science, applications must be identified pragmatically by close attention to the concerns of a particular discipline. They are often isolated by paradigmatic examples, the "exemplars" of [16], Postscript. Instead of applications we could speak equally well of classes of facts to be explained as in [34] or of problems to be solved as in [18].

Now let us make the unabashedly metaphysical assumption that we can speak of the set of all applications of science, that is the set of all classes of facts to be explained. Call this set $I_{A}$. Then the Absolute is the stage $S_{A}$ such that $K_{A}=\left\langle M_{A}, M_{p}\right\rangle$ and $I_{A}=M_{A}$. On the scientific analogy, the Absolute is just the theory that explains everything there is to explain. We might require only that $I_{A}$ be a subset of $M_{A}$, but we need the stronger 
assumption that $I_{A}=M_{A}$ in order to guarantee that the Absolute be unique, as it obviously must be.

This conception of the Absolute is very similar to Peirce's idea of the truth as that toward which science does or would converge. If science develops by accumulating more and more of the applications $I_{A}$, it is easy to view reality as represented by that theory which models all those applications, namely the Absolute. This holds even if some intended applications are dropped off along the way and even if there is radical conceptual change. A case for scientific realism could thus be based on the assumption of the existence of $I_{A}$.

That is obviously an enormous assumption. Can we make sense of the notion of the set of all classes of facts to be explained? Problems of selfapplication immediately arise, if among the facts to be explained we include the success of the Absolute in explaining facts. Absolute Knowledge would then somehow include knowledge about Absolute Knowledge, which threatens to set off an unmanageably infinite chain. A more modest Absolute is achieved if we identify it simply as a stage $S_{n}$ such that $K_{n}=$ $\left\langle M_{n}, M_{p}\right\rangle$ and it turns out that $M_{n}=I_{n}$. This stage picks out all and only the intended applications. Since there are no anomalies and no superflous models, supersession by another stage is unnecessary. The problem with this definition is that it guarantees neither existence nor the uniqueness of the Absolute, since no such stage $S_{n}$ might be reached, or some $S_{n}$ might be reached temporarily before new elements of $I_{n}$ are conceived which would restart the dialectic and perhaps lead to a later stable Absolute. Both these possibilities are incompatible with Hegel's assumptions about the dialectic of knowledge, which seem to require something like the set $I_{A}$. However, the weaker sense of Absolute seems more appropriate for scientific knowledge, since we do not in fact know whether science will or would converge as Peirce supposed, or whether it might converge temporarily and then diverge again.

Assuming a unique set $I_{A}$, the Absolute is unique. But what of the earlier stages in the dialectic? Clearly the definition of $N\left(S_{i}\right)$ above does not guarantee a unique negation of $S_{i}$, since any number of structures could satisfy clauses (1)-(3), and even the more restrictive clause (4) does not produce uniqueness. Although Hegel thought of the dialectic as uniquely determined, there is no general way to represent the necessity of each stage being succeeded by just the one which succeeds it. Only a pragmatic ac- 
count can be given of why a certain stage $S_{j}$ is the successor of $S_{i}$, just as in science we can only roughly describe how the anomalies faced by a theory lead to the production of a successor theory.

The growth of science occurs in time, but it is not clear whether the dialectic is essentially temporal. In the Logic, the pure dialectic of concepts is not intended to occur in time, but merely to represent the internal interconnection of concepts. The dialectic of consciousness in the Phenomenology has a more historical character, but even there Hegel usually seems to be working out conceptual rather than historical connections. Hence it is somewhat misleading to talk of a stage $S_{j}$ following a stage $S_{i}$ in the way in which one theory follows another in time. There is an ordering among conceptual stages in Hegel's dialectic, from the beginning stage up to the Absolute, but this ordering is conceptual or logical, not temporal.

Another potentially misleading feature of my formalism is that it does not depict how progress from stage to stage is generated. The existence of anomalies in $S_{i}$ is said to necessitate its supersession, but what is the motive force which leads one on to $S_{j}$ ? In science, the motive force is the critical faculty of scientists seeking better theories, but Hegel stresses that it is not we who discern the inadequacy of a stage of consciousness and move on to the next; rather, consciousness examines itself ([10], p. 141). Thus a formalism for the dialectic ought to represent the internally generated dynamic of dialectical development as well as the structure of succeeding stages. Routley and Meyer [24] speak of a "static dialectical logic", but such an entity is of a piece with round squares. To represent development more fully, we would need a system richer than a logical formalism. Perhaps a computer program could be developed to provide a dynamic model of the dialectical process, or of the process of scientific theory change.

To conclude, I shall briefly summarize the differences and similarities between Hegel's dialectic and the growth of scientific knowledge which the set-theoretic formalism has served to bring out. First the differences. (1) The dialectic preserves all previous applications. (2) Each dialectical stage is the necessary result of the previous one, in contrast to science where we allow the possibility that as a matter of historical accident a different theory could have filled a place in the history of science; and only a minimal leap from stage to stage is allowed. (3) The Absolute plays a teleological role in the dialectic and we are guaranteed to reach it. (4) The dialectic is 
spurred on by conceptual rather than empirical contradictions between claims and results.

Nevertheless, the similarities between the dialectic and the growth of scientific knowledge are remarkable. (1) Knowledge is viewed dynamically, as something which grows. (2) But growth is not simple accumulation since science and the dialectic display the twofold character of negation embodying both preservation and cancellation. (3) Growth is spurred by anomalies and the recognition of contradictions between what a theory or stage claims to do and what it actually does. (4) The bearers of knowledge are not sentences but complex structures. ${ }^{4}$

We have seen how the formalism for theory dynamics of Sneed and Stegmüller can be used to represent Hegel's notion of dialectical negation and contradiction, Aufheben, and the Absolute, as well as a notion of verisimilitude. The representation indicates both the fertility of the SneedStegmüller formalism and the contemporary relevance of Hegel for the philosophy of science. ${ }^{5}$

\section{University of Michigan-Dearborn}

\section{NOTES}

1 Marxian dialectics, as described for example in Engels [4], concerns the development of economic and social structures, not conceptual ones. My formalism is not intended to apply to a materialist dialectic, although rough analogies can be drawn.

2 Ordinarily in Tarskian semantics a model for a set $S$ of sentences is an interpretation consisting of a domain of objects $D$ and an assignment of objects and $n$-tuples of objects to constants and predicate letters of some specified language $L$, such that the sentences in $S$ are true for the interpretation. See for example [19], pp. 49-51. Here we talk of models independently of the sentences true for them. A model can then be considered as an ordered set $\left\langle D, R_{1}, R_{2}, R_{3}, \ldots\right\rangle$ where $D$ is a domain of objects as above, and each $R_{i}$ is a relation on $D$ understood as an $n$-tuple of members of $D$. Such a model is a representation of a situation independently of any sentential description. See for example [38], p. 107.

3 Clause (4) and most of the rest of this paragraph was suggested by John McCumber.

${ }^{4}$ In Sneed and Stegmüller, the conceptual structures are set-theoretic. See [35] for an argument that more elaborate data structures of the sort discussed in recent work in Artificial Intelligence are required for an account of the nature of scientific theories.

${ }^{5}$ I have benefitted greatly in writing this paper from numerous suggestions of John McCumber. I am also grateful to very helpful anonymous referees, to Jay Drydyk, and to commentators at the 1979 Canadian Philosophical Association Meeting, especially Eric Dayton. For further discussion of historical epistemology, see [33]. 


\section{REFERENCES}

[1] Asenjo, F. G., 'Dialectic Logic', Logique et Analyse 8 (1965), 321-326.

[2] Bernstein, Richard J., 'Why Hegel Now,' Review of Metaphysics 31 (1977), 29-60.

[3] Dubarle, D. and Doz, A., Logique et Dialectique, Librarie Larousse, Paris, 1972.

[4] Engels, F., Anti-Düring, Progress Press, Moscow, 1969.

[5] Feyerabend, P., 'Problems of Empiricism,' in R. Colodny (ed.), Beyond the Edge of Certainty, University of Pittsburgh Press, Pittsburgh, 1965, pp. 145-260.

[6] Gauthier, Y., 'Logique Hégélienne et Formalisation,' Dialogue 6 (1967-68), 151-165.

[7] Harris, E., 'Dialectic and Scientific Method,' Idealistic Studies 3 (1973), 1-17.

[8] Hegel, G., Lectures on History and Philosophy, 3 vols., trans. E. Haldane and F. Simson, Routledge and Kegan Paul, London, 1892.

[9] Hegel, G., The Logic of Hegel, (from Encyclopaedia) trans. W. Wallace, 2nd edn., Oxford University Press, Oxford, 1892.

[10] Hegel, G., The Phenomenology of Mind, trans. J. Baillie, Harper \& Row, New York, 1967.

[11] Hegel, G., The Philosophy of History, trans. J. Sibree, Dover, New York, 1956.

[12] Hegel, G., The Science of Logic, trans. A. Miller, George Allen and Unwin, London, 1969.

[13] Heidegger, M., Being and Time, trans. J. Macquarrie and E. Robinson, Harper \& Row, New York, 1962.

[14] Herzberger, H., 'Double Negation in Buddhist Logic,' Journal of Indian Philosophy 3 (1975), 3-16.

[15] Kosok, M., 'The Formalization of Hegel's Dialectical Logic,' in A. Maclntyre (ed.), Hegel, Doubleday, Garden City, 1972, 237-287.

[16] Kuhn, T. S., The Structure of Scientific Revolutions, 2nd edition, University of Chicago Press, Chicago, 1970.

[17] Lakatos, I., 'Falsification and the Methodology of Scientific Research Programmes,' in I. Lakatos and A. Musgrave (eds.), Criticism and the Growth of Knowledge, Cambridge University Press, Cambridge, 1970, 91-195.

[18] Laudan, L., 'Two Dogmas of Methodology,' Philosophy of Science 43 (1976) 585-597.

[19] Mendelson, E., Introduction to Mathematical Logic, Van Nostrand Reinhold, New York, 1954.

[20] Miller, D., 'Popper's Qualitative Theory of Verisimilitude,' British Journal for the Philosophy of Science 25 (1974), 166-177.

[21] Minsky, M., 'A Framework for Representing Knowledge,' in P. H. Winston, (ed.), The Psychology of Computer Vision, McGraw-Hill, New York, 1975, pp. 211-277.

[22] Peirce, C. S., Collected Papers, 8 vols., edited by C. Harthshorne, P. Weiss, and A. Burks, Harvard University Press, Cambridge, 1931-1958.

[23] Rescher, N., Dialectics, State University of New York Press, Albany, 1977.

[24] Routley, R. and Meyer, R., 'Dialectic Logic, Classical Logic, and the Consistency of the World,' Studies in Soviet Thought 16 (1976) 1-25.

[25] Seebohm, T. M., 'The Grammar of Hegel's Dialectic,' Hegel-Studien 11 (1975), 149180.

[26] Sneed, J. D., The Logical Structure of Mathematical Physics, D. Reidel, Dordrecht, 1971.

[27] Stegmüller, W., 'A Combined Approach to the Dynamics of Theories,' Theody and Decision 9 (1978), 39-75. 
[28] Stegmüller, W., The Structure and Dynamics of Theories, Springer-Verlag, New York, 1976.

[29] Suppe, F., 'The Search for Philosophical Understanding of Scientific Theories,' in F. Suppe (ed.), The Structure of Scientific Theories, 2nd edition, University of Illinois Press, 1977, 3-241.

[30] Suppes, P., Introduction to Logic, Van Nostrand, Princeton, N.J., 1957.

[31] Suppes, P., 'What is a Scientific Theory,' in S. Morgenbesser (ed.), Philosophy of Science Today, Basic Books, New York, 1967.

[32] Taylor, C., Hegel, Cambridge University Press, Cambridge, 1975.

[33] Thagard, P., 'Against Evolutionary Epistemology,' in P. Asquith and R. Giere (eds.), PSA 1980, vol. 1, Philosophy of Science Association, East Lansing, Mich., pp. 187196.

[34] Thagard, P., 'The Best Explanation: Criteria for Theory Choice,' Journal of Philosophy 75 (1978), 76-92.

[35] Thagard, P., 'Scientific Theories as Frame Systems,' tentatively to appear in a volume in the Pittsburgh Series in the Philosophy of Science.

[36] Thomason, S. K., 'Toward a Formalization of Dialectical Logic,' unpublished; abstract in Journal of Symbolic Logic 39 (1974), p. 204.

[37] van Fraassen, B. C., 'A Formal Approach to the Philosophy of Science,' in R. G. Colodny (ed.), Paradigms and Paradoxes, University of Pittsburgh Press, Pittsburgh. 1972, pp. 303-366.

[38] van Fraassen, B. C., Formal Semantics and Logic, Macmillan, New York, 1971.

[39] van Fraassen, B. C., 'To Save the Phenomena,' Journal of Philosophy 73 (1976), 623632.

[40] Winston, P. H., Artificial Intelligence, Addison-Wesley, Reading, Mass., 1977.

Manuscript submitted 14 May 1980

Final version received 9 January 1981 